\title{
Naturaleza y urbe: los escenarios del Persiles
}

Recibido: 12 de enero 2018

Aceptado: 14 de abril 2018

\section{Resumen:}

El trabajo presenta un acercamiento a la obra del Miguel de Cervantes Saavedra Los trabajos de Persiles y Segismunda (1617), mejor conocida como El Persiles, desde diferentes escenarios que tienen que ver con el tópico de la naturaleza: las cuevas, el mar, las islas, el locus amoenus, así como algunos aspectos que tienen que ver con la geografía.

Palabras clave: Cervantes; Persiles; naturaleza; cuevas; mar; islas; locus amoenus.

\section{Nature and city: the scenarios of Persiles}

\section{Abstract:}

The work presents an approach to the work of Miguel de Cervantes Saavedra Los trabajos de Persiles y Seguismunda (1617), known as El Persiles, from different scenarios that have to do with the topic of nature: the caves, the sea, the islands locus amoenus, and some aspects that have to do with geography.

Key words: Cervantes; Persiles; nature; caves; sea; islands; locus amoenus.

\section{(c) (i) (2)}

La Revista Estudios es editada por la Universidad de Costa Rica y se distribuye bajo una Licencia Creative Commons Atribución-NoComercial-CompartirIgual 3.0 Costa Rica. Para más información envíe un mensaje a 


\section{GENERALIDADES}

En la abundante bibliografía sobre el Persiles reaparece a menudo el tema de los espacios, la geografía, cartografía y cosmografía, y más secundariamente algunas observaciones sueltas sobre los escenarios naturales y urbanos en los que se desarrolla la complicada acción de esta novela de aventuras, habitualmente asociada al modelo bizantino"

La mayor parte de los comentaristas señalan la obvia estructura de los dos espacios fundamentales: el septentrión europeo para la primera parte (los dos primeros libros del Persiles) y el sur para la segunda (los libros III y IV). Estos dos espacios se vienen relacionando con la interpretación general del libro en dos vías principales: para quienes consideran el Persiles un relato alegórico que refleja la peregrinación de la vida humana, particularmente en términos religiosos o filosóficos (Avalle Arce, 1969, 1989; Vilanova, 1949; Nerlich, 2005...) el paso del norte infiel y bárbaro a la santa ciudad de Roma, «cielo de la tierra» (II, 7) es un camino de perfección según el itinerario de la «cadena del ser» (en palabras de Avalle Arce $)^{2}$ hacia la sublimación espiritual; para quienes ven el Persiles sobre todo como libro de entretenimiento o experimento narrativo (Lozano, 1998; Redondo, $2004 \ldots{ }^{3}$ los espacios se relacionan con problemas de verosimilitud ${ }^{4}$ : los

\footnotetext{
${ }^{1}$ No voy a entrar ahora en el género del Persiles o los modelos narrativos que asume. Ver Mata, 2004, para aspectos generales y una introducción global a la novela.

${ }^{2}$ Comp. Avalle Arce, 1969, p. 21: «hasta la geografía de la novela está ordenada en forma análoga a la cadena del ser. La mítica isla bárbara donde comienza la novela desaparece pronto para dar lugar a una Dinamarca o Irlanda de contornos más precisos pero no exactos. Estos lo encontramos al Ilegar a Portugal, España, Francia e Italia. Y por útimo Roma, "el cielo de la tierra" [...] un extremo de la cadena se hunde entre los bárbaros y el otro se exalta hasta el papado».

${ }^{3}$ El maestro José de Valdivielso, que algo sabía de religión y teología, en su aprobación del Persiles subraya significativamente la "apacible recreación», y apunta que de todos los libros de Cervantes ninguno es «es más ingenioso, más culto ni más entretenido» (p. 103). Citaré por la ed. del Persiles de Romero Muñoz. Cervantes, Miguel de, Los trabajos de Persiles y Sigismunda, ed. Carlos Romero Muñoz, Madrid, Cátedra, 1997, con algunas modificaciones de puntuación. La confusa interpretación hermética de Nerlich ha sido contestada por Lozano Renieblas, 2006.
}$$
\text { (c) (i) (2) }
$$

La Revista Estudios es editada por la Universidad de Costa Rica y se distribuye bajo una Licencia Creative Commons Atribución-NoComercial-Compartirlgual 3.0 Costa Rica. Para más información envíe un mensaje a revistaestudios.eeg@ucr.ac.cr. 
Especial: Naturaleza amena y naturaleza agreste en las letras hispánicas personajes y aventuras de índole más fantástica deben situarse en territorios poco conocidos, mientras que los más realistas pertenecen a espacios de la experiencia cotidiana de los lectores. La variedad de lugares, por lo demás, corresponde a la variedad de sucesos que se proponen en una trama 'bizantina' (Díez de Revenga, $2003)^{5 .}$

Lozano (1998) subraya que la imprecisión geográfica es propia del género literario y que problema esencial es la verosimilitud (que no estimula interpretaciones alegóricas). Por su lado Romero (1997, p. 38) intenta conciliar el escenario septentrional con el propósito de verosimilitud, la búsqueda del exotismo y las posibles dimensiones alegóricas de la novela...

Pero dejando esta discusión aparte, en la que tercian numerosos estudiosos, me interesa en esta oportunidad descender un poco más en detalle a los espacios naturales $^{6}$ y urbanos que configuran la acción del Persiles, y que presentan modalidades específicas más allá de la caracterización general de norte y sur.

Los espacios de la naturaleza y de la urbe en el mundo septentrional (y alguna incursión en el meridional) ${ }^{7}$

Los primeros sucesos de la novela plantean ya cierta complejidad de espacios naturales y mixtos: cuevas, estrechos marítimos, tempestades, mar sesgo y cielo claro, oscuridad, prados deleitosos, incendios forestales...

\footnotetext{
${ }^{4}$ Sobre esta cuestión que tanto preocupa a Cervantes, ver los agudos comentarios de Nadine Ly, 2003.

${ }^{5}$ Un examen de la variedad de espacios en relación con la teoría neoaristotélica de la ficción y el enfoque de la factual fiction moderna en Dunne, 2016, que plantea algunas conclusiones discutibles.

${ }_{6}^{6}$ Poco de interés tiene el comentario de Carilla, Emilio, 1954, donde distingue tres tipos de paisajes: el tópico renacentista, el mar y la «abigarrada naturaleza barroca».

${ }_{7}$ Aunque en este apartado me ocupo sobre todo del mundo del norte, reúno los comentarios de algunos motivos que también aparecen en el itinerario del sur (cuevas, locus amoenus...).
}

\section{(c) (i) ()}

La Revista Estudios es editada por la Universidad de Costa Rica y se distribuye bajo una Licencia Creative Commons Atribución-NoComercial-Compartirlgual 3.0 Costa Rica. Para más información envíe un mensaje a revistaestudios.eeg@ucr.ac.cr. 


\section{LAS CUEVAS}

El primer espacio natural que aparece es la cueva prisión en la que están los cautivos de los bárbaros. Se trata de un agujero profundo con una boca estrecha tapada por una roca, espacio de la naturaleza corrompido por la violencia de su función $^{8}$, y cuya limitación y oscuridad se oponen al claro cielo y aire abierto y saludable que la rodea (pp. 117-118). Esta gruta funge como escenario de la barbarie, pero no siempre las cavernas son lugares negativos. En realidad, cuando los personajes se hallen en un marco agreste la cueva ofrece un refugio seguro ante los peligros y las inclemencias de una naturaleza a menudo hostil. De este modo la cueva del español Antonio constituye la antítesis de la mazmorra. Huyendo del incendio y la violencia desatada en la Isla Bárbara los peregrinos son guiados a través de una espaciosa cueva y una serie de túneles naturales hasta salir a un campo raso (p. 148). Caminando a su través «llegaron a una altísima peña, al pie de la cual descubrieron un anchísimo espacio o cueva, a quien servían de techo y de paredes las mismas peñas» (p. 149). Es el rancho de la familia de Antonio, inculto, sí, pero abrigado por pieles de animales, iluminado por teas, y provisto de lo necesario para la vida según el modelo de la Edad de Oro:

Las vajillas que en la cena sirvieron, ni fueron de plata ni de pisa: las manos de la bárbara y bárbaro pequeños fueron los platos, y unas cortezas de árboles, un poco más agradables que de corcho, fueron los vasos. Quedose Candia lejos, y sirvió en su lugar agua pura, limpia y frigidísima (pp. 149-150)

\footnotetext{
${ }^{8}$ No es ni inteligible ni aceptable la identificación de esta cueva con las «profundidades del intelecto", el cual estaría personificado en el personaje de Cloelia, ni viene al caso asimilarla a la caverna de Platón (como hace Uceda, 2015). Más bien evoca el espacio de la barbarie, probablemente inspirado en la gruta de Polifemo de la Odisea, también bloqueada por una gran piedra.
}

\section{(c) (i) (9) (2)}

La Revista Estudios es editada por la Universidad de Costa Rica y se distribuye bajo una Licencia Creative Commons Atribución-NoComercial-Compartirlgual 3.0 Costa Rica. Para más información envíe un mensaje a 


\section{Especial: Naturaleza amena y naturaleza agreste en las letras hispánicas}

En el cap. 6 del libro I Periandro observa este refugio y confirma su calidad de locus amoenus en versión rústica:

vio que era hecho y fabricado de la naturaleza como si la industria y el arte le hubieran compuesto: era redondo, cercado de altísimas y peladas peñas, y, a su parecer, tanteó que bojaba poco más de una legua, todo lleno de árboles silvestres que ofrecían frutos, si bien ásperos, comestibles a lo menos. Estaba crecida la yerba, porque las muchas aguas que de las peñas salían las tenían en perpetua verdura (p. 163)

Es evidente que esta cueva es un espacio de seguridad y de amor familiar. No tienen sentido, por tanto, interpretaciones como las de Sanesteban (2015, pp. 47) quien argumenta (contra el propio texto) que "por el hecho de describirnos la morada de los bárbaros como una cueva y mostrarnos que todavía no tenían moneda acuñada Cervantes hace que nos imaginemos este lugar y su gente como inclemente y cruel"9

En el cap. 18 del libro III, la cueva del astrólogo Soldino abre su boca dentro de una ermita emplazada en una selva cuyos árboles dan apacible sombra a un prado «amenísimo» (p. 607). La cueva, ya situada en un locus amoenus, da entrada a otro espacio de la misma calidad, evocado más ampliamente para alojar el tópico del beatus ille y el sosiego de la naturaleza retirada; es la cueva refugio del sabio ${ }^{10}$ :

\footnotetext{
${ }^{9}$ Pero nótese que Ricla y Costanza se califican constantemente a lo largo de la novela de compasivas y prontas a las lágrimas de ternura (I, 7, 21; III, 2; 21; IV, 2, etc.). Tampoco veo mayor justificación a lo que dice Casalduero (cit. en la nota de Romero a este pasaje, p. 163), quien ve en esta cueva una representación de la Iglesia de las catacumbas o la Iglesia asediada por la herejía.

10 En todas las culturas la cueva aparece como espacio de retiro espiritual para los ascetas, eremitas y meditadores. Los Ejercicios espirituales de San Ignacio se originan en la cueva de Manresa, por ejemplo. No hace falta documentar este sentido de la cueva, que es contrario al mito de la caverna platónica.
}

\section{(c) (i) (9) (2)}

La Revista Estudios es editada por la Universidad de Costa Rica y se distribuye bajo una Licencia Creative Commons Atribución-NoComercial-Compartirlgual 3.0 Costa Rica. Para más información envíe un mensaje a 
Especial: Naturaleza amena y naturaleza agreste en las letras hispánicas

todo aquel escuadrón de damas y caballeros, bajó por las gradas de la escura cueva y, a menos de ochenta gradas, se descubrió el cielo luciente y claro y se vieron unos amenos y tendidos prados que entretenían la vista y alegraban las almas. [...] con mis brazos y con mi continuo trabajo, cavé la cueva y hice mío este valle, cuyas aguas y cuyos frutos con prodigalidad me sustentan. Aquí, huyendo de la guerra, hallé la paz; la hambre que en ese mundo de allá arriba (si así se puede decir) tenía halló aquí a la hartura; aquí, en lugar de los príncipes y monarcas que mandan el mundo, a quien yo servía, he hallado a estos árboles mudos, que, aunque altos y pomposos, son humildes; aquí no suena en mis oídos el desdén de los emperadores, el enfado de sus ministros; aquí no veo dama que me desdeñe ni criado que mal me sirva; aquí soy yo señor de mí mismo; aquí tengo mi alma en mi palma, y aquí por vía recta encamino mis pensamientos y mis deseos al Cielo (pp. 608-609)

No será la gruta el único espacio ambivalente en la novela.

\section{EL MAR}

Ámbito natural de doble faz es también el mar, escenario fundamental en el trazado aventurero del Persiles. Esta doble cualidad ha sido percibida por los estudiosos, pero a mi juicio no se ha comprendido bien la jerarquía de las dos evocaciones marítimas.

La primera es la tormenta. Cuando los bárbaros trasladan a Periandro de la isla prisión a la Isla Bárbara se desata una furiosa borrasca que deshace las balsas:

Levantaron remolinos las aguas, pelearon entre sí los contrapuestos vientos, anegáronse los bárbaros, salieron los leños del atado prisionero al mar abierto, pasábanle las olas por cima, no solamente impidiéndole ver el cielo, pero negándole el poder pedirle tuviese compasión de su desventura. Y sí tuvo, pues las continuas y furiosas ondas que

La Revista Estudios es editada por la Universidad de Costa Rica y se distribuye bajo una Licencia Creative Commons Atribución-NoComercial-CompartirIgual 3.0 Costa Rica. Para más información envíe un mensaje a 
Especial: Naturaleza amena y naturaleza agreste en las letras hispánicas

a cada punto le cubrían no le arrancaron de los leños y se le llevaron consigo a su abismo; que, como llevaba atadas las manos a las espaldas, ni podía asirse ni usar de otro remedio alguno. (p. 121)

Capítulo II Enseguida sale la balsa maltrecha de Periando a mar abierto impulsada por las violentas olas y, de manera algo sorprendente, entra en una zona sosegada en la que topa con el navío de Arnaldo.

No es la única vez que Cervantes yuxtapone una borrasca y el mar tranquilo sin solución de continuidad. En el libro II, 1 (p. 275) «comenzó la borrasca con tanta furia que no pudo ser prevenida de la diligencia y arte de los marineros; y así, a un mismo tiempo les cogió la turbación y la tormenta», borrasca que vuelca el barco en que va Auristela con sus compañeros, que enseguida es arrastrado «de las olas, ya mansas y recogidas» a una playa del reino del rey Policarpo, donde son rescatados (p. 279).

Mar tormentoso y mar sesgo son las dos modalidades contrastivas de este ámbito natural que Cervantes propone en el Persiles. Servera considera predominante el mar calmo, hasta el punto de distinguir tres marcos paisajísticos, entre los cuales destaca el marco paisajístico «de bonanza» (1990, p. 298), y cita con aprobación a Alberto Navarro (1981, p. 41) para quien "resulta interesante observar que descuellan y menudean [descripciones] del mar sesgo, blando y propicio [...] y escasean las descripciones de naufragios y tempestades, de los que sólo hallamos un extenso ejemplo" (II, 1).

En realidad menudean tanto mares propicios como tormentosos en el Persiles ${ }^{11}$, y en varias ocasiones se justifica semejante alternancia como imagen de los voltarios sucesos de la vida humana: "que la inconstancia de nuestras vidas y la

\footnotetext{
${ }^{11}$ Tormentas: I, 1, 2, 5, 6, 8, II, 1; IV, 12; mares calmos y tranquilos: I, 1, 2, 5, 6, 9, 11, 17, 18; II, 15, 21 ... (como otras veces indico libro y capítulo).

\section{(c) (i) (2)}

La Revista Estudios es editada por la Universidad de Costa Rica y se distribuye bajo una Licencia Creative Commons Atribución-NoComercial-CompartirIgual 3.0 Costa Rica. Para más información envíe un mensaje a revistaestudios.eeg@ucr.ac.cr.
} 
Especial: Naturaleza amena y naturaleza agreste en las letras hispánicas del mar simbolizan en no prometer seguridad ni firmeza alguna largo tiempo". (II, $17)^{12}$

Las evocaciones cervantinas de las tormentas las considera Carilla (1954, p. 212) sin mucho fundamento «momentos en que se eleva sobre el lugar común de tanto paisaje retórico» ${ }^{13}$; Moner ha analizado un caso particular de simbolismo psicológico14... pero la tormenta dsempeña sobre todo una función narrativa, y en este sentido me interesa señalar que las dos categorías de mar no son del mismo rango: el modelo dominante (narrativamente funcional) es el mar tormentoso ${ }^{15}$ en cuanto agente que traza un trayecto aleatorio de los peregrinos ${ }^{16}$. De ahí que no le interese a Cervantes un reflejo «realista» de los fenómenos naturales: en cuanto la borrasca ha cumplido su cometido de desviar el camino de los aventureros, puede hacer su inmediata aparición el mar bonancible sin necesidad de insistir más en las descripciones tormentosas, que no son excesivamente elaboradas en el Persiles. La característica del mar como espacio en el que se mueven los personajes es que - a diferencia de la tierra - no tiene caminos: los itinerarios marítimos son azarosos. El mar en calma no es motor de la acción, no cambia los trayectos; las tormentas sí, que empujan de un lado a otro a los peregrinos, en un laberinto confuso punteado de islas casi siempre hostiles, desiertas, nevadas o

\footnotetext{
${ }^{12}$ Al mismo símbolo recurre el polaco Ortel Banedre para expresar el transcurso de su accidentada vida (p. 497). Para las lecturas emblemáticas del mar y la navegación en el Persiles ver Arellano, Ignacio, "Elementos emblemáticos en la Galatea y el Persiles», Bulletin of Spanish Studies, 81, 2004, pp. 571-583. http://dx.doi.org/10.1080/1475382042000254382

${ }^{13}$ Son bastante retóricas y sucintas en el Persiles. Para un examen de este motivo de la tormenta en el Siglo de Oro ver Fernández Mosquera, 2006.

${ }^{14}$ Moner, 2014, estudia la tormenta súbita de I, 23-24; II, 1-2 como metáfora del ataque de celos de Auristela al enterarse de las atenciones de Sinforosa con Periandro, en un mecanismo de permutación de dos estereotipos (la descripción de la tormenta y el motivo de los celos). Ver también Christine Marguet, quien comenta este valor metafórico de este episodio pero señala que el proceso más habitual en Cervantes es la desmetaforización de los elementos naturales (2011, p. 560).

${ }^{15}$ Semejante función desempeña el hostil mar glacial de Noruega, que encierra a los navegantes (p. 385).

${ }_{16}$ Poco más que paráfrasis del texto cervantino ofrece Nebot (1996) en su comentario del itinerario de los peregrinos.
}

La Revista Estudios es editada por la Universidad de Costa Rica y se distribuye bajo una Licencia Creative Commons Atribución-NoComercial-Compartirlgual 3.0 Costa Rica. Para más información envíe un mensaje a 
Especial: Naturaleza amena y naturaleza agreste en las letras hispánicas

escabrosas. $Y$ en efecto, en la primera parte del Persiles la naturaleza que corresponde al elemento tierra se presenta en forma de archipiélago, otro modelo coherente con el género bizantino y de aventuras.

\section{LAS ISLAS}

No hará falta acopiar mucha documentación para ponderar la calidad de las islas como espacios de la maravilla. Como apunta Redondo (2004, p. 78) «la isla es el lugar en que lo maravilloso, lo fabuloso puede desarrollarse, porque constituye un universo de por sí, exótico por definición» ${ }^{17}$. Estos espacios, lo mismo que las grutas y el mar, son ambivalentes y puede asociarse «al paraíso o al infierno, la cárcel o tumba, sociedad bárbara o sociedad ideal», como indica Soupault (2003, p. 1001$)^{18}$, quien relaciona estos lugares cervantinos con el género de los islarios o relatos geográficos del Renacimiento, que a su vez recogen motivos frecuentes en la épica antigua y moderna, en los libros de caballerías, o en las Etiópicas de Heliodoro, libro con el que Cervantes quería competir. Soupault precisa que el islario del Persiles incluye lugares reales (Inglaterra, Irlanda, Groenlandia...), semireales (como Golandia, isla de realidad «borrosa») y ficticios. Hay una numerosa bibliografía ${ }^{19}$ que intenta identificar las islas cervantinas manejando diversas fuentes cartográficas como los textos de los hermanos Zeno, Olao Magno, y otros que sin duda conocía Cervantes, quien utiliza muchos detalles con función verosimilizadora extraídos de estas fuentes histórico-geográficas conocidas en la época (Díaz de Alda, 2001, p. 877). Pero el sentido global del uso cervantino

\footnotetext{
${ }^{17}$ Comp. Soupault, 2004, p. 1002: «Es sabido que el motivo de la isla se suele asociar al espacio de la aventura desde la Odisea y entre sus seguidores, como Heliodoro en su Historia etiópica de Teágenes y Cariclea, con el que quiso competir nuestro autor. Luego aperece como un lugar privilegiado de la aventura caballeresca y, en las novelas bizantinas como Clareo y Florisea de Núñez de Reinoso, en 1552.»

${ }_{18}$ Soupault considera fundador del género islario a Cristóbal Buondelmonti con su libro Liber insularum archipielagi (1420). Otros islarios menciona en p. 1003.

${ }^{19}$ Remito solo a Servera, 1990 y Díaz de Alda, 2001, con suficiente documentación sobre el tema.
}

\section{(c) (7) (2) (-)}

La Revista Estudios es editada por la Universidad de Costa Rica y se distribuye bajo una Licencia Creative Commons Atribución-NoComercial-Compartirlgual 3.0 Costa Rica. Para más información envíe un mensaje a 


\section{Especial: Naturaleza amena y naturaleza agreste en las letras hispánicas} coincide sobre todo con el de otros textos coetáneos y tiene que ver con el efecto narrativo de lo maravilloso y sorprendente, la curiosidad y el deleite.

En las misceláneas y repertorios de curiosidades auriseculares (baste remitir por ejemplo a los últimos tratados del Jardín de flores curiosas de Torquemada, otra fuente cervantina) son frecuentes los capítulos dedicados a las geografías exóticas, como la de los países septentrionales que el citado Olao Magno había extendido. Rodrigo Fernández de Santaella ${ }^{20}$, canónigo de la catedral de Sevilla, al dedicar a principios del XVI al conde de Cifuentes su traducción del libro de los viajes de Marco Polo, consciente de esta afición, repara en que

Entre las cosas que más deleitan los varones nobles deseosos de leer e saber [...] es leer por autor auténtico las partidas del mundo. Mayormente aquellas que no alcanzamos a ver y que de pocos fueron vistas e tratadas [...] Las cuales, según las que en nuestra Europa vemos, oviéramos por consejas increíbles, si lo que en nuestros días de muchas islas del gran mar oceano occidental por nuestros muy ínclitos reyes se ha descubierto...

Toda la primera parte del Persiles transcurre en un archipiélago confuso, verdadero laberinto de islas, para las cuales (en su mayor parte) es superfluo buscar referentes reales. Baste enumerar las principales que recorren los peregrinos: en la categoría hostil se suceden la isla prisión, la Isla Bárbara, la isla desierta de los licántropos (p. 160), la innominada isla cercana a la Bárbara (p. 169), la isla nevada (p. 174), otra isla nevada (p. 249), isla despoblada (p. 189), isla del Fuego (p. 367)... A otros modelos más positivos pertenecen la isla del rey Policarpo (p. 261), asociada por algún estudioso — creo que excesivamente- a la utopía perfecta ${ }^{21}$, la de las ermitas (p. 393) descrita como un verdadero locus

\footnotetext{
${ }^{20}$ Marco Polo, Libro de las cosas maravillosas, p. 3.

${ }^{21}$ Soupault, 2004, p. 1006: «En efecto, la isla del rey Policarpo, tal como está descrita en el capítulo 22 del primer libro, es un modelo de monarquía democrática: el rey debe ser elegido entre
}

\section{(c) (i) (2)}

La Revista Estudios es editada por la Universidad de Costa Rica y se distribuye bajo una Licencia Creative Commons Atribución-NoComercial-CompartirIgual 3.0 Costa Rica. Para más información envíe un mensaje a revistaestudios.eeg@ucr.ac.cr. 
Especial: Naturaleza amena y naturaleza agreste en las letras hispánicas amoenus de la Edad de Oro (p. 404), y — última evocación-Tule y Frislanda, patrias de los protagonistas a las que regresan para vivir casados y contentos hasta que bisnietos les alargaron los días en su feliz posteridad (p. 730). La mayoría de las islas corresponden al género hostil, de obstáculos y peligros, definidas por fenómenos naturales agresivos (vientos, nieve, hielos, frío, oscuridad) y caracterizadas por su condición salvaje, llenas de riscos, peñas, y montes escabrosos ${ }^{22}$, deshabitadas o con pobladores bárbaros: "Están todos aquellos mares casi cubiertos de islas, todas o las más despobladas; y las que tienen gente, es rústica y medio bárbara, de poca urbanidad y de corazones duros e insolentes..." $(I, 11)$

Cervantes aporta pocos detalles y muy elementales: no le interesa demasiado el paisaje como tal, sino el mecanismo asignado a las islas (semejante al del mar) de motor del relato. Las islas del Persiles, aunque estén ancladas en los mares septentrionales desempeñan sobre todo una función narrativa dinámica.

En el juego de contrastes que de algún modo refleja el itinerario vital de los personajes no solo existen los lugares hostiles. Con cierta frecuencia Cervantes acude al topos del locus amoenus, que explora de nuevo en distintas variedades.

los ciudadanos más virtuosos. No deja de parecerse a la utopía inventada un siglo antes por Tomás Moro".

${ }^{22}$ El paisaje de la naturaleza septentrional es casi siempre inhóspito en el Persiles. Una cala muy incompleta pero significativa arroja para los dos primeros libros 6 menciones de «riscos» (ninguna en la segunda parte); 11 de «peñas» (solo 2 en la segunda parte); 8 de «montañas» (solo 2 en la segunda parte); unas 15 menciones significativas (quitando alguna metáfora) de «nieve» (ninguna significativa en la segunda parte); otras 15 de «hielo», todas en los dos primeros libros; etc.

\section{(@) $\odot \Theta \odot$}

La Revista Estudios es editada por la Universidad de Costa Rica y se distribuye bajo una Licencia Creative Commons Atribución-NoComercial-CompartirIgual 3.0 Costa Rica. Para más información envíe un mensaje a revistaestudios.eeg@ucr.ac.cr. 
Especial: Naturaleza amena y naturaleza agreste en las letras hispánicas

\section{EL TOPOS DEL LOCUS AMOENUS}

Ya he mencionado algunos aspectos de este topos a propósito de las cuevas refugio de Antonio (en la Isla Bárbara) y del sabio Solino, pero conviene añadir algunos comentarios, pues se trata de un importante espacio multiforme ${ }^{23}$.

Las modalidades mencionadas podrían considerarse ejemplos del locus amoenus rústico, en la tradición de la Edad de Oro. Hallamos de nuevo este modelo en la isla de las ermitas, desarrollado con cierto detallismo:

salieron a ver desde aquella cumbre la amenidad de la pequeña isla, que sólo podía bojar hasta doce millas, pero tan llena de árboles frutíferos, tan fresca por muchas aguas, tan agradable por las yerbas verdes y tan olorosa por las flores, que en un igual grado y a un mismo tiempo podía satisfacer a todos cinco sentidos.

Pocas horas se había entrado por el día, cuando los dos venerables ermitaños llamaron a sus huéspedes, y, tendiendo dentro de la ermita verdes y secas espadañas, formaron sobre el suelo una agradable alfombra, quizá más vistosa que las que suelen adornar los palacios de los reyes. Luego tendieron sobre ella diversidad de frutas, así verdes como secas, y pan no tan reciente que no semejase bizcocho, coronando la mesa asimismo de vasos de corcho con maestría labrados, de fríos y líquidos cristales llenos. El adorno, las frutas, las puras y limpias aguas, que, a pesar de la parda color de los corchos, mostraban su claridad, y la necesidad juntamente, obligó a todos, y aun les forzó, por mejor decir, a que alrededor de la mesa se sentasen. (p. 404)

Variedad de este mismo sería el locus amoenus «realista», de ambiente rústico pero más cercano a la experiencia, que es el que acoge a Feliciana de la Voz y sus compañeros en la segunda parte de la novela, y cuya tranquilidad es quebrada por un episodio trágico:

${ }^{23}$ Ver Fernández Mosquera, 1996.

La Revista Estudios es editada por la Universidad de Costa Rica y se distribuye bajo una Licencia Creative Commons Atribución-NoComercial-CompartirIgual 3.0 Costa Rica. Para más información envíe un mensaje a revistaestudios.eeg@ucr.ac.cr. 
Dábales asiento la verde yerba de un deleitoso pradecillo, refrescábales los rostros el agua clara y dulce de un pequeño arroyuelo que por entre las yerbas corría, servíanles de muralla y de reparo muchas zarzas y cambroneras, que casi por todas partes los rodeaba: sitio agradable y necesario para su descanso, cuando, de improviso, rompiendo por las intricadas matas, vieron salir al verde sitio un mancebo vestido de camino, con una espada hincada por las espaldas, (p. 465)

Más cerca del tópico literario habitual (no rústico) es el espacio ameno que acoge las fiestas de bodas de los pescadores en II, 12, también profanado por la cuadrilla de salteadores que roban a Auristela y otras mujeres:

La sazón del tiempo, que era la del verano, la comodidad del sitio, el resplandor de la luna, el susurro de las fuentes, la fruta de los árboles, el olor de las flores, cada cosa de éstas de por sí, y todas juntas, convidaban a tener por acertado el parecer de que allí estuviésemos el tiempo que las fiestas durasen. ( $p$. 355)

Cervantes amplía los tratamientos del motivo con otros modelos simbólicos, fantásticos o relacionados con teorías artísticas.

Uno de los lugares amenos más llamativos de la novela es la isla soñada que describe Periandro en II, 15. En realidad al comienzo de la narración se presenta como espacio de la realidad: después de indicar que se entregan al reposo («entregamos al reposo y al sueño los trabajados cuerpos») continúa «En fin, nos desembarcamos todos y pisamos la amenísima ribera» (p. 378) lo que da a entender que después de haber dormido desembarcan. Sigue la descripción del paisaje maravilloso, en el que en cierto momento irrumpe una escena alegórica, de la que despierta el narrador, que se encuentra a bordo del navío (p. 382), es decir, que no ha desembarcado y todo ha sido sueño. Cervantes ha elaborado la escena para demorar la condición soñada del paisaje hasta el final de la

La Revista Estudios es editada por la Universidad de Costa Rica y se distribuye bajo una Licencia Creative Commons Atribución-NoComercial-CompartirIgual 3.0 Costa Rica. Para más información envíe un mensaje a 
Especial: Naturaleza amena y naturaleza agreste en las letras hispánicas secuencia, reforzando la impresión de maravilla. La más notable característica de esta versión del locus amoenus es su calidad literaria de isla encantada, la abundancia metafórica, el barroquismo colorista y preciosista puesto de relieve por Servera, quien lo compara con Góngora (1990, p. 303-305) ${ }^{24}$ :

En fin, nos desembarcamos todos y pisamos la amenísima ribera, cuya arena, vaya fuera todo encarecimiento, la formaban granos de oro y de menudas perlas. Entrando más adentro, se nos ofrecieron a la vista prados cuyas yerbas no eran verdes por ser yerbas, sino por ser esmeraldas, en el cual verdor las tenían, no cristalinas aguas, como suele decirse, sino corrientes de líquidos diamantes formados, que cruzando por todo el prado sierpes de cristal parecían. Descubrimos luego una selva de árboles de diferentes géneros, tan hermosos que nos suspendieron las almas y alegraron los sentidos; de algunos pendían ramos de rubíes que parecían guindas o guindas que parecían granos de rubíes; de otros pendían camuesas, cuyas mejillas la una era de rosa, la otra de finísimo topacio; en aquel se mostraban las peras, cuyo olor era de ámbar y cuyo color de los que forman el cielo cuando el sol se traspone.

En resolución, todas las frutas de quien tenemos noticia estaban allí en su sazón, sin que las diferencias del año las estorbasen: todo allí era primavera, todo verano, todo estío sin pesadumbre y todo otoño agradable, con estremo increíble. Satisfacía a todos nuestros cinco sentidos lo que mirábamos: a los ojos, con la belleza y la hermosura; a los oídos con el ruido manso de las fuentes y arroyos y con el son de los infinitos pajarillos, que con no aprendidas voces formado, los cuales, saltando de árbol en árbol y de rama en rama, parecía que en aquel distrito tenían cautiva su libertad y que no querían ni acertaban a cobrarla; al olfato con el olor que de sí despedían las yerbas, las flores y los frutos; al gusto con la prueba que hicimos de la suavidad dellos; al tacto con tenerlos en las manos, con que nos parecía tener en ellas las perlas

\footnotetext{
${ }^{24}$ No parece necesario relacionar directamente este pasaje con otros lugares paradisiacos que menciona Romero en su nota (p. 379, nota 5), como el canto XXVI de La Araucana o el X del Orlando furioso. No veo que estos hayan tenido "concreta eficacia» sobre la visión de Persiles, como tampoco es necesario aducir el jardín de Alcínoo de la Odisea. Son motivos tópicos muy extendidos.
}

\section{(c) (i) (2)}

La Revista Estudios es editada por la Universidad de Costa Rica y se distribuye bajo una Licencia Creative Commons Atribución-NoComercial-CompartirIgual 3.0 Costa Rica. Para más información envíe un mensaje a 


\section{Especial: Naturaleza amena y naturaleza agreste en las letras hispánicas}

del Sur, los diamantes de las Indias y el oro del Tíbar. (pp. 378-379)

Semejante estilo hiperbólico aplica a la descripción de Aranjuez, lugar este de la realidad española de la época, que manifiesta los resultados de la fusión de arte y naturaleza y que refleja la afición renacentista y barroca por los jardines y el arte topiaria, tema de conocidas composiciones de Soto de Rojas y otros poetas ${ }^{25}$ :

Nuestros peregrinos pasaron por Aranjuez, cuya vista, por ser en tiempo de primavera, en un mismo punto les puso la admiración y la alegría; vieron de iguales y estendidas calles, a quien servían de espaldas y arrimos los verdes y infinitos árboles: tan verdes, que las hacían parecer de finísimas esmeraldas; vieron la junta, los besos y abrazos que se daban los dos famosos ríos Henares y Tajo; contemplaron sus sierras [sic] de agua; admiraron el concierto de sus jardines y de la diversidad de sus flores; vieron sus estanques, con más peces que arenas, y sus esquisitos frutales, que por aliviar el peso a los árboles tendían las ramas por el suelo; finalmente, Periandro tuvo por verdadera la fama que deste sitio por todo el mundo se esparcía. (pp. 514-515)

Particular categoría es el locus amoenus a lo divino evocado en la Canción a la Virgen de Guadalupe, inserto en una estructura emblemática correspondiente a la simbología mariana. Se suceden en el poema (pp. 480-481) entre otros elementos, pozos, fuentes perenales, huertos cerrados de sanos frutos, y jardines con palmas, cedros, cinamomos, plátanos y rosas de Jericó... que componen un espacio paradisiaco, pero que fundamentalmente remiten a las lecturas simbólicas basadas sobre todo en textos bíblicos y patrísticos.

Del locus amoenus rústico, relacionado o no con el motivo de la Edad de Oro, hasta la versión a lo divino, pasando por la onírica, Cervantes construye distintas versiones acordes con la calidad genérica de los pasajes.

\footnotetext{
${ }^{25}$ Para el motivo del jardín ver Assunto, 1981; Hansmann, 1989; Pedraza Jiménez, 1998; Alvarado Teodorika, 2000.

\section{(c) (1) 8 (9)}

La Revista Estudios es editada por la Universidad de Costa Rica y se distribuye bajo una Licencia Creative Commons Atribución-NoComercial-CompartirIgual 3.0 Costa Rica. Para más información envíe un mensaje a
} revistaestudios.eeg@ucr.ac.cr. 
Especial: Naturaleza amena y naturaleza agreste en las letras hispánicas

\section{LOS ITINERARIOS DEL SUR}

La segunda parte del Persiles traslada a los peregrinos de los espacios septentrionales al sur de Europa: Portugal, España, Francia, Italia, en camino a Roma.

Aunque algún estudioso ha sugerido que estos nuevos paisajes pueden ser exóticos para los personajes que provienen del norte, creo que el lector $-\mathrm{y}$ el narrador- los perciben como contrapuestos a los septentrionales en tanto resultan bien conocidos, y además pertenecen a la tierra y no al mar. Quiere decirse que ahora los itinerarios pueden marcarse y definirse y Cervantes marca los hitos mencionando por su nombre la mayoría de los lugares: Lisboa, Guadalupe, Talavera, la Sagra, Toledo, Ocaña, Aranjuez, Alicante, Cartagena, Valencia, Villarreal, Perpiñán, Milán, Luca, Roma... ${ }^{26}$.

Ahora bien: lo familiar de los espacios no interrumpe el propósito de la admiratio: si en los helados archipiélagos nórdicos los peregrinos protagonizaban estupendas aventuras, en las tierras españolas les sucedrán casos igualmente «nuevos» y «extraños» («Peregrinos. Su viaje por España. Sucédenles nuevos y estraños casos», III, 2, p. 440), aunque ahora serán fundamentalmente espectadores de las peripecias de Feliciana de la Voz, Ortel Banedre, el conde herido de bala, Ambrosia Agustina..., Rubertino, el conde Domicio, Feliz Flora, el conde Lamberto de Escocia o en Italia el caso de Isabela Castrucha y Andrea Marulo... entre otros «casos de admiración» que se suceden.

La mención de las ciudades o poblaciones —núcleos urbanos- no implica descripciones detalladas de dichos espacios, que merecen poca atención del narrador. Se elogia a Lisboa (p. 430) y otras ciudades pero curiosamente los peregrinos evitan entrar en Toledo («no quiso Periandro que entrasen en Toledo, porque así se lo pidió Antonio el padre», p. 513), tampoco visitan Valencia («Cerca

${ }^{26}$ Ver para los itinerarios de la parte española Canavaggio, 2003.

\section{(c) (i) (2)}

La Revista Estudios es editada por la Universidad de Costa Rica y se distribuye bajo una Licencia Creative Commons Atribución-NoComercial-Compartirlgual 3.0 Costa Rica. Para más información envíe un mensaje a revistaestudios.eeg@ucr.ac.cr. 
Especial: Naturaleza amena y naturaleza agreste en las letras hispánicas de Valencia llegaron, en la cual no quisieron entrar por escusar las ocasiones del detenerse», p. 561), ni el santuario de Monserrat («las santísimas montañas de Monserrate, que adoraron con devoción cristiana, sin querer subir a ellas, por no detenerse, p. 563)...

En suma, estos lugares son meros puntos de referencia para ordenar al relato y dar entrada a las sucesivas historias. Por más que Farinelli considere a Cervantes uno de los «grandes cantores de la montaña sagrada catalana» o Astrana Marín crea que la descripción del monasterio de Guadalupe es «sencillamente portentosa», nada de esto se justifica con los perfunctorios textos que evocan dichos lugares $^{27}$. El caso de Guadalupe es significativo: ¿qué comunica el narrador sobre este famoso monasterio en III, 5. Se dice que el valle en que está situado lo cierran altísimas sierras, que el monasterio es grande y suntuoso y guarda una imagen santísima de la Virgen, y que sus paredes están llenas de exvotos. Es todo. Y es muy poco.

El empeñoso razonamiento de Egido (1998) que traza un forzado paralelo entre la «peregrinación» de la imagen guadalupana, que va de Roma al monasterio extremeño, y la de los protagonistas que van de Guadalupe a Roma, explicando que Auristela es un reflejo de la Virgen apocalíptica de Guadalupe ${ }^{28}$, -lo que convertiría al monasterio en un lugar esencial para la comprensión del Persiles y el supuesto trayecto de perfección de los peregrinos- es poco admisible. Entre numerosas lucubraciones bastante discutibles sobre significados marianos, de la

\footnotetext{
${ }^{27}$ Ver notas de Romero, p. 563, n. 8; p. 474, n. 4.

${ }^{28}$ Egido, 1998, p. 24: «La imagen guadalupana había paseado hacía siglos por las calles de Roma en tiempos de San Gregorio, salvando a los enfermos de peste antes de llegar a tierras sevillanas y cacereñas. Cervantes, que debió conocer la leyenda, unió así Guadalupe con Roma como principio y fin de una peregrinación de ida y vuelta que devolvía a una nueva Eva, virgen y dispuesta a la elevación de los sacramentos como Auristela, también paseante por Roma y nueva versión, a lo humano, de la Virgen apocalíptica e inmaculada»; y p. 29: «Tras los diversos lugares marianos visitados por los protagonistas, el lugar de Dios premiaba la purificación del cuerpo y del alma, la victoria sobre el espacio y la naturaleza que, en el andar de los protagonistas, había significado la búsqueda de la Nueva Jerusalén». No veo nada de esto en el texto del Persiles.
}

\section{(c) (i) (2)}

La Revista Estudios es editada por la Universidad de Costa Rica y se distribuye bajo una Licencia Creative Commons Atribución-NoComercial-Compartirlgual 3.0 Costa Rica. Para más información envíe un mensaje a revistaestudios.eeg@ucr.ac.cr. 
Especial: Naturaleza amena y naturaleza agreste en las letras hispánicas Reconquista y americanos ${ }^{29}$, Egido justifica en buena parte el paralelo susodicho con el argumento de que la publicación del Persiles casi coincide con la proclamación de la Inmaculada Concepción "El hecho de que en 1615 se proclamara la Inmaculada Concepción hace más curioso el sentido mariano de la última obra cervantina ceñida al amplio arco de advocaciones y celebraciones marianas a lo largo y ancho de la Península en las fechas previas a su publicación." (1998, p. 30)

Pero en 1615 no se proclama la Inmaculada Concepción; solo se publica un decreto de Paulo V sobre indulgencias concedidas a la oración de la Inmaculada. En 1616 el papa prohíbe mantener en público opiniones contrarias, etc. Todos estos años están llenos de proclamaciones, apoyos y defensas de la Inmaculada, y no hay un momento específico que pudiera guiar la lectura del Persiles. La proclamación dogmática de la Inmaculada, por cierto, habrá de esperar a la definición de Pío IX en la bula Inneffabilis Deus del 8 de diciembre de 1854.

Mejor corresponde al texto cervantino lo que afirma Redondo (2004, p. 86): "Es de suponer que el autor nunca puso los pies en Guadalupe y que su información fue escueta. Pero esto no tendría mayor interés si se pusieran de relieve las manifestaciones del culto rendido a la famosa Virgen. En realidad, no pueden ser más tópicas y podrían utilizarse con relación a cualquier templo..."

La urbe principal en todo el libro, la que se presenta como culminación del viaje de los peregrinos es Roma, cuyo sentido ha provocado cierto debate entre los comentaristas de la novela.

Una de las interpretaciones —ligada a la lectura alegórica de la peregrinación como camino de perfeccionamiento espiritual - es la evidente de ciudad cabeza

${ }^{29}$ Egido (1998, p. 28): «supo unir en el cañamazo novelesco la historia del Monasterio guadalupano y de su Virgen con las resonancias que ambos implicaban en la historia de la Reconquista y en la de los descubrimientos americanos, ensartándolos de modo natural en la peregrinación hacia la Ciudad Eterna».

\section{(c) (i) (2)(2)}

La Revista Estudios es editada por la Universidad de Costa Rica y se distribuye bajo una Licencia Creative Commons Atribución-NoComercial-CompartirIgual 3.0 Costa Rica. Para más información envíe un mensaje a 
Especial: Naturaleza amena y naturaleza agreste en las letras hispánicas del catolicismo, donde Persiles y Sigismudo cumplen su voto y contraen matrimonio después de refinar su adoctrinamiento religioso.

La exaltación de la Roma sagrada se evoca ciertamente en algunos lugares como las siete iglesias que visitaban los peregrinos (p. 676), o el templo de San Pablo (p. 722), y se concentra especialmente en el soneto de un peregrino:

¡Oh grande, oh poderosa, oh sacrosanta, alma ciudad de Roma! A ti me inclino, devoto, humilde y nuevo peregrino, a quien admira ver belleza tanta.

Tu vista, que a tu fama se adelanta, al ingenio suspende, aunque divino, de aquel que a verte y adorarte vino con tierno afecto y con desnuda planta.

La tierra de tu suelo, que contemplo con la sangre de mártires mezclada, es la reliquia universal del suelo.

No hay parte en ti que no sirva de ejemplo de santidad, así como trazada de la ciudad de Dios al gran modelo. (p. 655)

Pero no falta razón a quienes, desde diferente perspectiva, hacen hincapié en la otra cara de Roma, la de las cortesanas y la corrupción de costumbres. Más espacio que a la descripción de los templos ${ }^{30}$ dedica el narrador a la del camarín y Ionja de la cortesana Hipólita, verdadero gabinete de curiosidades en el que se desarrolla la tentación a Periandro (superada por el honesto galán, cuya visita a la casa de la cortesana, si embargo, no se justifica):

\footnotetext{
${ }^{30}$ Comp. Lozano Renieblas, 1998, p. 185: «la Roma que presenta Cervantes [...] no es la Roma papal que ha querido ver la crítica [...] ni la Roma santa que auguraban los devotos deseos de los personajes, sino la otra cara de Roma, la que más le interesaba para poner a prueba a su protagonista: la Roma de la prostitución»; Redondo, 2004, p. 88: «Roma, como centro activo de la catolicidad, aparece muy poco».
}

\section{(C) $(\Theta \odot \odot$}

La Revista Estudios es editada por la Universidad de Costa Rica y se distribuye bajo una Licencia Creative Commons Atribución-NoComercial-CompartirIgual 3.0 Costa Rica. Para más información envíe un mensaje a 
Especial: Naturaleza amena y naturaleza agreste en las letras hispánicas Abrieron la sala, y a lo que después Periandro dijo, estaba la más bien aderezada que pudiese tener algún príncipe rico y curioso en el mundo. Parrasio, Polignoto, Apeles, Zeuxis y Timantes tenían allí lo perfecto de sus pinceles, comprado con los tesoros de Hipólita, acompañados de los del devoto Rafael de Urbino y de los del divino Micael Ángelo: riquezas donde las de un gran príncipe deben y pueden mostrarse. Los edificios reales, los alcázares soberbios, los templos magníficos y las pinturas valientes son propias y verdaderas señales de la magnanimidad y riqueza de los príncipes, prendas, en efeto, contra quien el tiempo apresura sus alas y apresta su carrera, como a émulas suyas, que a su despecho están mostrando la magnificencia de los pasados siglos.

¡Oh Hipólita, solo buena por esto! Si entre tantos retratos que tienes, tuvieras uno de tu buen trato, y dejaras en el suyo a Periandro, que, asombrado, atónito y confuso andaba mirando en qué había de parar la abundancia que en la lonja veía en una limpísima mesa, que de cabo a cabo la tomaba la música que de diversos géneros de pájaros en riquísimas jaulas estaban, haciendo una confusa, pero agradable armonía. En fin, a él le pareció que todo cuanto había oído decir de los huertos Hesperideos, de los de la maga Falerina, de los Pensiles famosos, ni de todos los otros que por fama fuesen conocidos en el mundo, no llegaban al adorno de aquella sala y de aquella lonja. (pp. 683-685)

En las últimas páginas del Persiles reaparece el mundo septentrional y se cierra la historia de los protagonistas declarándose sus patrias (Tule y Frislanda), a las que regresan después de su matrimonio para vivir felices luengos años.

\section{(c) (i) (2)}

La Revista Estudios es editada por la Universidad de Costa Rica y se distribuye bajo una Licencia Creative Commons Atribución-NoComercial-CompartirIgual 3.0 Costa Rica. Para más información envíe un mensaje a 


\section{FINAL}

\section{Especial: Naturaleza amena y naturaleza agreste en las letras hispánicas}

El círculo se ha cerrado, y la estructura del viaje se cumple como es habitual: el retorno al hogar es la culminación del peregrinaje aventurero. El viaje no tendría sentido sin el regreso. El héroe se lanza a sus aventuras para poder regresar. La estructura mítica es aquí circular: el héroe debe volver lleno de nuevos conocimientos y experiencias al lugar de donde salió, allí donde mejor puede ser reconocida su victoria y su excelencia. Se trata, en el fondo, de un proceso de afirmación de la propia identidad, que ha crecido en el desarrollo de las aventuras y que se confirma en el ámbito original.

Sin negar, por tanto, la función mítica del viaje como perfeccionamiento espiritual, ni ciertas dimensiones "contrarreformistas» en muchos motivos del Persiles, hay que precisar que el primer movimiento de las aventuras de los protagonistas no obedece a un propósito religioso sino a una estrategia amorosa, para evitar la boda de Sigismunda con Maximino. La peregrinación a Roma se presenta en principio como una excusa, o cuando menos, algo adventicio al principal objetivo de la reina Eustoquia y la pareja de enamorados:

Abrazola la Reina, contó su respuesta a Persiles, y entre los dos concertaron que se ausentasen de la isla antes que su hermano viniese, a quien darían por disculpa, cuando no la hallase, que había hecho voto de venir a Roma a enterarse en ella de la fe católica, que en aquellas partes setentrionales andaba algo de quiebra, jurándole primero Persiles que en ninguna manera iría en dicho ni en hecho contra su honestidad. (p. 717)

En ese fundamental propósito de amor humano pueden insertarse los motivos religiosos - abundantes en la novela - pero no parece fundada una interpretación propiamente alegórica sin forzar abusivamente el texto.

El Persiles no es una alegoría: es un relato de aventuras cuyo principio constructivo básico es el movimiento, el dinamismo. Por eso las visiones estáticas

\section{(c) (i) (2) (2)}

La Revista Estudios es editada por la Universidad de Costa Rica y se distribuye bajo una Licencia Creative Commons Atribución-NoComercial-CompartirIgual 3.0 Costa Rica. Para más información envíe un mensaje a revistaestudios.eeg@ucr.ac.cr. 
Especial: Naturaleza amena y naturaleza agreste en las letras hispánicas de la naturaleza y de la urbe fungen como hitos ordenadores de la acción, pero no le preocupan en sí mismos al narrador de esta selva de aventuras, que dedica poca atención a los detalles, limitándose a menciones con poco contenido descriptivo. Hay que tener en cuenta que en la acelerada acumulación de sucesos, los personajes tienen poco sosiego para demorarse en la fruición estética de los paisajes naturales o urbanos. En realidad pudiera decirse que el enfoque cervantino es el inverso del que se explica al comienzo del III, 10 donde leemos que «Las peregrinaciones largas siempre traen consigo diversos acontecimientos, y, como la diversidad se compone de cosas diferentes, es forzoso que los casos lo sean». Pero más que justificar la diversidad de casos por la duración del viaje lo que hace el narrador es utilizar la longitud y complicación del itinerario para justificar la inserción de numerosos casos capaces de admirar a los lectores con su diversidad y extrañeza, eso sí, procurando guisar estas acciones «con tanta puntualidad y gusto, y con tanta verisimilitud que, a despecho y pesar de la mentira, que hace disonancia en el entendimiento, forme una verdadera armonía» (p. 532).

En este sentido la variedad de los entornos - fantásticos o familiares, realistas o simbólicos, apoyados en datos prácticos de la cartografía de la época o enteramente ficticios, oníricos o costumbristas...- obedece a un proyecto de variedad estilística, pero en cuanto a su función narrativa no distingue esencialmente los paisajes septentrionales de los meridionales.

\section{(c) (i) (2)}

La Revista Estudios es editada por la Universidad de Costa Rica y se distribuye bajo una Licencia Creative Commons Atribución-NoComercial-CompartirIgual 3.0 Costa Rica. Para más información envíe un mensaje a 
Especial: Naturaleza amena y naturaleza agreste en las letras hispánicas

\section{BIBLIOGRAFÍA}

Alvarado Teodorika, Tatiana, «El jardín en el teatro aurisecular. Las comedias mitológicas de Calderón», en La cultura del Barroco. Los jardines: arquitectura, simbolismo y literatura, Huesca, Instituto de estudios Altoaragoneses, 2000, pp. 187-226.

Arellano, Ignacio, «Elementos emblemáticos en la Galatea y el Persiles», Bulletin of Spanish Studies, 81, 2004, pp. 571-583. http://dx.doi.org/10.1080/1475382042000254382

Assunto, Rosario, Filosofia del giardino e filosofia nel giardino. Saggi di teoria e storia dell'estetica, Roma, Bulzoni, 1981.

Avalle Arce, Juan Bautista, «La alegoría del Persiles», en Homenaje al Profesor Antonio Vilanova, I, ed. Adolfo Sotelo Vázquez y Marta Cristina Carbonell, Barcelona, PPU, 1989, pp. 45-55.

Avalle Arce, Juan Bautista, Introducción a la ed. Cervantes, Miguel de, Los trabajos de Persiles y Sigismunda, Madrid, Castalia, 1969.

Canavaggio, Jean, «L’Espagne du Persiles», Langues néo-latines, 327, 2003, pp. 21-38.

Carilla, Emilio, «Naturaleza y retórica en el Persiles», Revista Universidad Pontificia Bolivariana, 19.70, 1954, pp. 209-215, https://revistas.upb.edu.co/index.php/upb/article/view/3835/3422.

\section{(c) (i) (2)}

La Revista Estudios es editada por la Universidad de Costa Rica y se distribuye bajo una Licencia Creative Commons Atribución-NoComercial-CompartirIgual 3.0 Costa Rica. Para más información envíe un mensaje a revistaestudios.eeg@ucr.ac.cr. 
Especial: Naturaleza amena y naturaleza agreste en las letras hispánicas

Cervantes, Miguel de, Los trabajos de Persiles y Sigismunda, ed. Carlos Romero Muñoz, Madrid, Cátedra, 1997.

Díaz de Alda, María del Carmen, «Última Thule y el contexto nórdico de Los trabajos de Persiles y Sigismunda», en Volver a Cervantes: Actas del IV Congreso Internacional de la Asociación de Cervantistas, coord. por Antonio Pablo Bernat Vistarini, Vol. 2, Palma de Mallorca, Universidad de las Islas Baleares, 2001, pp. 875-886.

Díez de Revenga, Javier, «La imaginación en Lope de Vega: Los espacios de El peregrino en su patria», en Loca Ficta: los espacios de la maravilla en la Edad Media y el Siglo de Oro, ed. Ignacio Arellano, Madrid, Iberoamericana, 2003, pp. 189-202.

Dunne, Jorg, «Estudios del espacio. Imaginación cartográfica y ficción cosmopolítica en el Persiles de Cervantes», Ínsula, 829-830, 2016, pp. 2023.

Egido, Aurora, «Poesía y peregrinación en el Persiles. El templo de la Virgen de Guadalupe», en Actas del Tercer Congreso Intemacional de la Asociación de Cervantistas, ed. A. Bernat Vistarini, Palma, Universitat de les Illes Balears, 1998, pp. 13-41.

Fernández Mosquera, Santiago, «La modificación del lugar ameno en la narración cervantina», en Paisaje, juego y multilingüismo, en Actas del $X$ Congreso Internacional de la Sociedad Española de Literatura General y Comparada, ed. Darío Villanueva y Fernando Cabo, Santiago de Compostela,

\section{(c) (i) (2)}

La Revista Estudios es editada por la Universidad de Costa Rica y se distribuye bajo una Licencia Creative Commons Atribución-NoComercial-Compartirlgual 3.0 Costa Rica. Para más información envíe un mensaje a revistaestudios.eeg@ucr.ac.cr. 
Especial: Naturaleza amena y naturaleza agreste en las letras hispánicas Universidad de Santiago, Consorcio de Santiago de Compostela, 2 vols., 1996, I, pp. 303-317.

Fernández Mosquera, Santiago, La tormenta en el Siglo de Oro. Variaciones funcionales de un tópico, Madrid/Frankfurt am Main, Iberoamericana/Vervuert, 2006.

Hansmann, Wilfried, Jardines del renacimiento y el barroco, Madrid, Nerea, 1989.

Lozano Renieblas, Isabel, «El Persiles hermético», Cervantes. Bulletin of the Cervantes Society of America, 26.1, 2006, pp. 277-284.

Lozano Renieblas, Isabel, Cervantes y el mundo del Persiles, Alcalá de Henares, Centro de Estudios Cervantinos, 1998.

Ly, Nadine, «Le miroitement de la vraisemblance dans le Persiles ou de l'invention d'un ressort romanesque», Les Langues Néo-Latines, 327, 2003, p. 39-72.

Marco Polo, Libro de las cosas maravillosas, trad. de R. de Santaella [1503], Madrid, Sociedad de Bibliófilos Españoles, 1947.

Marguet Christine, «Metamorfosis y correspondencias; cosmografía y mesurabilidad: discurso poético y científico en el Persiles de Cervantes», en Visiones y revisiones cervantinas: actas selectas del VII Congreso Internacional de la Asociación de Cervantistas, coord. por Christoph Strosetzki, Alcalá de Henares, Centro de Estudios Cervantinos, 2011, pp. 555-564.

\section{(C) $(00)$}

La Revista Estudios es editada por la Universidad de Costa Rica y se distribuye bajo una Licencia Creative Commons Atribución-NoComercial-CompartirIgual 3.0 Costa Rica. Para más información envíe un mensaje a revistaestudios.eeg@ucr.ac.cr. 
Especial: Naturaleza amena y naturaleza agreste en las letras hispánicas

Mata, Carlos, «El Persiles de Cervantes, paradigma del arte narrativo barroco», en

Temas del barroco, ed. Ignacio Arellano y Eduardo Godoy, Madrid, Iberoamericana, 2004, pp. 197-219.

Moner, Michel, «Malabarismos narrativos e innovaciones poéticas: el relato de tempestad en Los trabajos de Persiles y Sigismunda», en Comentarios a Cervantes: Actas selectas del VIII Congreso Internacional de la Asociación de Cervantistas, coord. por Emilio Martínez Mata, María Fernández Ferreiro, Oviedo, Fundación María Cristina Masaveu Peterson, 2014, pp. 228-235.

Navarro, Alberto, Cervantes entre el Persiles y el Quijote, Salamanca, Editorial Universidad de Salamanca, 1981.

Nebot Calpe,Natividad, «Itinerario de la peregrinación en el Persiles», en Caminería hispánica: actas del II Congreso Internacional de Caminería Hispánica, coord. por Manuel Criado de Val, Vol. 3, Guadalajara, AACHE Ediciones, 1996, pp. 205-218.

Nerlich, Michael, Persiles descodificado o la divina comedia de Cervantes, Madrid, Hiperión, 2005.

Pedraza Jiménez, Felipe, «De Garcilaso a Lope: los jardines poéticos en tiempos de Felipe II», en: Felipe II, el Rey íntimo. Jardín y naturaleza en el siglo XVI, Aranjuez, Sociedad estatal para la conmemoración de los centenarios de Felipe II y Carlos V, 1998, pp. 307-329.

\section{(c) (7) (-)}

La Revista Estudios es editada por la Universidad de Costa Rica y se distribuye bajo una Licencia Creative Commons Atribución-NoComercial-CompartirIgual 3.0 Costa Rica. Para más información envíe un mensaje a 
Especial: Naturaleza amena y naturaleza agreste en las letras hispánicas

Redondo, Augustin, «El Persiles, libro de entretenimiento peregrino», en Peregrinamente peregrinos, ed. Alicia Villar, Palma de Mallorca, Asociación de cervantistas, 2004, pp. 67-102.

Romero, Carlos, ed. Cervantes, Miguel de, Los trabajos de Persiles y Sigismunda, Madrid, Cátedra, 1997.

Sanesteban, Chus, «El espacio en Los trabajos de Persiles y Sigismunda», Narrativas: revista de narrativa contemporánea en castellano, 39, 2015, pp. 45-54.

Servera, José, «El paisaje soñado en Los trabajos de Persiles y Sigismunda», en Actas del I Coloquio Internacional de la Asociación de Cervantistas, Barcelona, Anthropos, 1990, pp. 295-305.

Soupault, Isabelle, "Peregrinar por las islas: el relato insular en el Persiles», en Peregrinamente peregrinos: actas del $V$ Congreso Internacional de la Asociación de Cervantistas, coord. por Alicia Villar Lecumberri, Lisboa, Fundaçâo Calouste Gulbenkian, Vol. 1, 2004, pp. 1001-1016.

Uceda, Pascual, «Historia septentrional: una hipótesis sobre la estructura profunda del Persiles», Anales cervantinos, 47, 2015, pp. 209-247.

Vilanova, Antonio, «El peregrino andante en el Persiles de Cervantes», Boletín de la Real Academia de Buenas Letras de Barcelona, 22, 1949, pp. 97-159.

\section{(c) (i) (2)}

La Revista Estudios es editada por la Universidad de Costa Rica y se distribuye bajo una Licencia Creative Commons Atribución-NoComercial-CompartirIgual 3.0 Costa Rica. Para más información envíe un mensaje a 